subjects could sit unassisted. At 24 months after gene therapy, $64 \%$ of subjects achieved head control, 50\% could sit unassisted, and 18\% could stand with support. At 60 months after gene therapy, $75 \%$ of subjects achieved head control, $67 \%$ of subjects could sit unassisted, $25 \%$ of subjects could stand with support, and $8 \%$ subjects could walk with support. In contrast, only $4 \%$ of the subjects in the NHDB control group achieved key motor milestones $(\mathrm{P}<0.0001)$. These results demonstrate that the attainment of milestones is sequential in nature and that the percentage of patients achieving more advanced milestones (eg, standing with support, walking with assistance) increases over time.

The number of patients achieving full head control and sitting unassisted was significantly higher in patients treated with eladocagene exuparvovec compared to the NHDB control group. The results indicate that patients with AADC deficiency treated with eladocagene exuparvovec show significant improvements in achieving motor milestones, impacting the natural history of disease.

\section{FEBRILE CONVULSIONS AND INFLUENZA A OR B- ARE THERE DIFFERENCES?}

Monika Kukuruzovic*

\subsection{6/archdischild-2021-europaediatrics.391}

Influenza viruses may cause predominantly respiratory illness, but could also be responsible for numerous neurologic symptoms and complications. All children who are admitted in hospital with symptoms and changes in their neurological status, especially during the flu season, should be tested even if their respiratory problems are mild or non-existent. The most common neurological complications are febrile convulsions.

In this study, we retrospectively reviewed patients with febrile seizures over two periods from 2008-2011. and 2018.2020. during a flu season (November-March) who had a proven influenza $A$ or $B$ virus and who were hospitalized at the Department of Neuropediatrics of the UHC Sestre milosrdnice. We aimed to find out if there were differences in the type of influenza depending on the period and what features of febrile convulsions were associated with influenza type A or type $\mathrm{B}$ and to emphasize the need for optimized prevention.

In the period 2008-2011. at our Department there were 480 patients hospitalized, 99 of them with febrile seizures. In the period 2017.-2020.

(end of February) there were 659 patients, 102 of whom with febrile seizures. The first period had 37 influenza positive patients (15 patients influenza type A, 5 influenza type B, 7 unknown) and the second period had 44 patients with proven influenza (36 patients had influenza type A, 8 patients had influenza type B).

In hospitalized children during both periods, influenza type A was associated with a higher incidence of febrile seizures than influenza type $\mathrm{B}$. The reason could be that influenza type $\mathrm{A}$ is more neurotropic than influenza type $\mathrm{B}$ and more often causes febrile seizures. Our finding of similar incidence of febrile seizures during both periods can be explained by continued poor prevention and fear of vaccination. This study indicates that there is a need to raise awareness of better prevention of influenza virus transmission.

\section{HEREDITARY NEUROPATHY WITH LIABILITY TO PRESSURE PALSY}

Iva Šeparović*, M Kukuruzović, M Malenica. UHC sestre milosrdnice

\subsection{6/archdischild-2021-europaediatrics.392}

A Case Report I.Šeparovićn ${ }^{1}$, M.Kukuruzović ${ }^{1}$, M.Malenica $^{1}$ 1.UHC Sestre milosrdnice, Zagreb, Croatia Hereditary neuropathy with liability to pressure palsies (HNPP) is a rare, autosomal dominant disease, with prevalence estimated between 0.84 and 16 per 100,000, affecting peripheral myelin, which manifests as recurrent, and usually transient, painless motor and/or sensory neuropathies. Neuropathies are triggered by minor trauma or repetitive movements with compression and traction of peripheral nerves. The most frequent forms of presentation affect the peroneal and the ulnar nerves. Brachial plexopathy occurs in 11\%-20\% and is an unusual clinical manifestation; bilateral presentation is even rarer. Genetic tests are available to aid in diagnosis as molecular analysis has identified a deletion in the chromosome $17 \mathrm{p} 11.2$ in the majority of these patients. The deletion of chromosome $17 \mathrm{p} 11.2$ in hereditary neuropathy with liability to pressure palsies appears to be the reciprocal meiosis product of the $17 \mathrm{p} 11.2$ duplication seen in Charcot-Marie-Tooth disease Type 1a. We present the clinical case of a 16-year-old boy, football player. It was his first episode, HNPP presenting with foot drop and palsy both nerves peroneus after distortion articulation talocruralis.

Electromyography studies showed subacute axonal lesions of both nerves peroneus. The diagnosis of hereditary neuropathy with liability to pressure palsy was confirmed by PMP22 deletion of chromosome $17 \mathrm{p} 11.2$. He started motor rehabilitation and avoidance of stressing factors with progressive recovery. These palsies generally resolve without surgical intervention but orthopedist decided to make decompression of nerve. The recovery followed quickly. After one-year follow up, he was completely asymptomatic. A case report is presented of a patient with this disorder to promote awareness and recognition that this entity should be considered in patients with multiple nerve palsies.

\section{NEUROLOGICAL PRESENTATION OF WILSON'S DISEASE IN A PEDIATRIC PATIENT WITH SILENT CIRRHOSIS}

Maša Malenica*, Orjena Žaja, Marina Mataia, Tomislav Gregurić, Monika Kukuruzović, Iva Šeparović, Barbara Perše, Ana Kovačević. UHC Sestre milosrdnice

\subsection{6/archdischild-2021-europaediatrics.393}

A previously healthy 13-year-old girl with a 5-month-history of hypersalivation, dysarthria, tremor, thrombocytopenia, and leukopenia was admitted to our hospital. On examination we noticed hypersalivation with an incomplete closing of the mouth, dysarthria, splenomegaly, resting and action tremor of the upper extremities, and slightly weakened hand grip. Jaundice, palmar erythema, or spider-like nevus were not present. Her body mass index was in the 1 st percentile (Z-score 2.21). Magnetic resonance (MRI) of the brain showed abnormal T2 hyperintensity in the basal ganglia, mesencephalon, and pons. Abdominal ultrasound indicated diffuse changes in liver parenchyma with circular edges, regenerative nodes, splenomegaly, and suspected portal hypertension, without ascites. Fibrosis was confirmed by liver fibroscan and abdominal MRI, which corresponded to laboratory findings (lower prothrombin 